phenotype was not stable, unlike asthma, neutrophilic was the most common inflammatory phenotype in infants with wheezing, and it was no business of eosinophilia.

\section{0-167b INFLUENCE OF MONTELUKAST ON THE RELIABILITY OF SKIN PRICK TESTING WITH INHALANT ALLERGENS}

${ }^{1} \mathrm{D}$ Stamatovic, ${ }^{2} \mathrm{~K}$ Starinac, ${ }^{3} \mathrm{M}$ Vujosevic, ${ }^{4} \mathrm{Z}$ Vujnovic Zivkovic. ${ }^{1}$ General Pediatric, Private Practice "Primum Vivere", Krusevac, Serbia; ${ }^{2}$ Preschool Department, Service for Health Care of Children and Youth, Krusevac, Serbia; ${ }^{3}$ Pediatric Department, General Hospital, Bar, Montenegro; ${ }^{4}$ Pediatric Department, Medical Faculty, Kosovska Mitrovica, Serbia

\subsection{6/archdischild-2014-307384.235}

Background and aims There is no much data in the literature about the effects of montelukast on the skin reactivity to inhaled allergens. We analysed whether the skin reactivity to allergens significantly changed after 30 days of daily application of montelukast.

Methods Thirty children with asthma (7-14 y) and with skin reactivity to inhaled allergens were receiving $5 \mathrm{mg}$ of montelukast daily for 30 days. Skin prick testing was done before and after therapy. Size of the papule was measured at twentieth minute after allergen application as quantitative (mean of the largest and normally set diameter on it) and qualitative-bimodal: positive/negative (cut-point: $3 \mathrm{~mm}$ ). The control group consisted of children of the same age $(n=30)$ with positive skin reactivity who did not receive any medication and has been tested in the same way. The size of the papule, and the number of positive/ negative tests for both groups were compared before and after therapy. The frequency of test conversion in both directions (crossing of positive to negative and vice versa) in the experimental group was compared to the control group.

Results After thirty days of montelukast therapy the size of the papule in both groups was not significantly changed $(p>0.05)$. Compared to the control group, in the experimental group, there was no significant difference in the change of skin reactivity to allergens, either quantitatively $(p>0.05)$, or qualitatively $(\mathrm{p}>0.05)$ evaluated.

\section{Child Protection}

\section{0-168 RISK AND RESILIENCE FACTORS FOR EARLY CHILD DEVELOPMENT: A COMMUNITY-BASED COHORT STUDY IN ALBERTA, CANADA}

SW McDonald, H Kehler, SC Tough. Pediatrics, University of Calgary, Calgary, Canada

\subsection{6/archdischild-2014-307384.236}

Background and aims One in six children experience developmental problems at school entry. Early intervention is more effective than later remediation; however, to date, we lack a comprehensive understanding of risk and protective factors. The objectives of this study were to describe the key risk factors for poor child development at age 12 months and to identify factors that reduce the potentially adverse influence of poor maternal mental health and low socioeconomic status on child development.

Methods We used data from the All Our Babies (AOB) study, a prospective pregnancy cohort in Calgary, Alberta. Five domains of child development at age 12 months were assessed via parent report using the Ages and Stages Questionnaire (ASQ) from approximately 1500 mothers. The associations between putative risk factors and poor child development were examined in bivariate and multivariable analyses. A bivariate resilience analysis was also conducted to identify factors related to positive child development in the presence of maternal mental health or sociodemographic risk.

Results Key risk factors for poor child development at age 12 months included poor maternal mental health during pregnancy, and low community resource use and lack of adult interaction in the first postpartum year. In addition to parenting efficacy, uptake of community resources and increased adult interaction were protective of poor child development among children most at risk for this outcome.

Conclusions As many of the identified risk and protective factors are modifiable, these results can inform community based strategies to optimise early childhood development.

\section{0-168a YOUNG PEOPLE AND FAMILY INVOLVEMENT IN PAEDIATRIC RESEARCH NETWORKS: OUTCOMES OF A SURVEY AMONG ENPR-EMA NETWORKS}

${ }^{1}$ B Pelle, ${ }^{2} \mathrm{P}$ Helms, ${ }^{3}$ J Drabwell, ${ }^{4}$ J Preston, ${ }^{4} \mathrm{M}$ Turner, ${ }^{1} \mathrm{I}$ Eichler. ${ }^{1}$ Paediatric Medicines, European Medicines Agency, London, UK; ${ }^{2}$ Scottish Children's Research Network, Scottish Children's Research Network, Aberdeen, UK; ${ }^{3}$ International Patient Organisation for Primary Immunodeficiencies, International Patient Organisation for Primary Immunodeficiencies, Downderry, UK; ${ }^{4}$ NIHR Clinical Research Network, Children, Liverpool, UK

\subsection{6/archdischild-2014-307384.237}

Background and aims Engaging and involving young people in clinical research has many benefits including greater understanding of young people's perspectives and improvements in study design and the quality of clinical research. ${ }^{1}$ The nature and extent of support for the engagement of young people in research in Europe is unclear.

Methods A survey was sent to members of the European network of paediatric research at the EMA (Enpr- EMA), ${ }^{2}$ (Figure 1).

Results While more than half of the responding networks $(\mathrm{N}=17)$ actively involve young people/families, only 3 networks have dedicated resources and strategies in place to support this activity, ${ }^{3-5}$ (Table 1). Activities undertaking with young people/ families in Enpr-EMA networks are summarised in Table 2.

Conclusions The majority of networks requested guidelines on establishing and maintaining young people's advisory groups and/or identified the need for training for this activity. Responsible and effective involvement of young people/family in paediatric clinical research has been established only in some European networks and should be generalised urgently.

Acknowlegements Not applicable.

Abstract 0-168a Table 1 Engagement of young people and family members in Enpr-EMA networks

\begin{tabular}{llll}
\hline Young people/family members engagement & Total & Yes & No \\
\hline Involvement/consultation with young people/family & 17 & 8 & 9 \\
Dedicated staff for young people/family involvement & 17 & 7 & 10 \\
Specific budget for young people/family involvement & 17 & 3 & 14 \\
Specific strategies for young people/family involvement & 17 & 3 & 14 \\
\hline
\end{tabular}




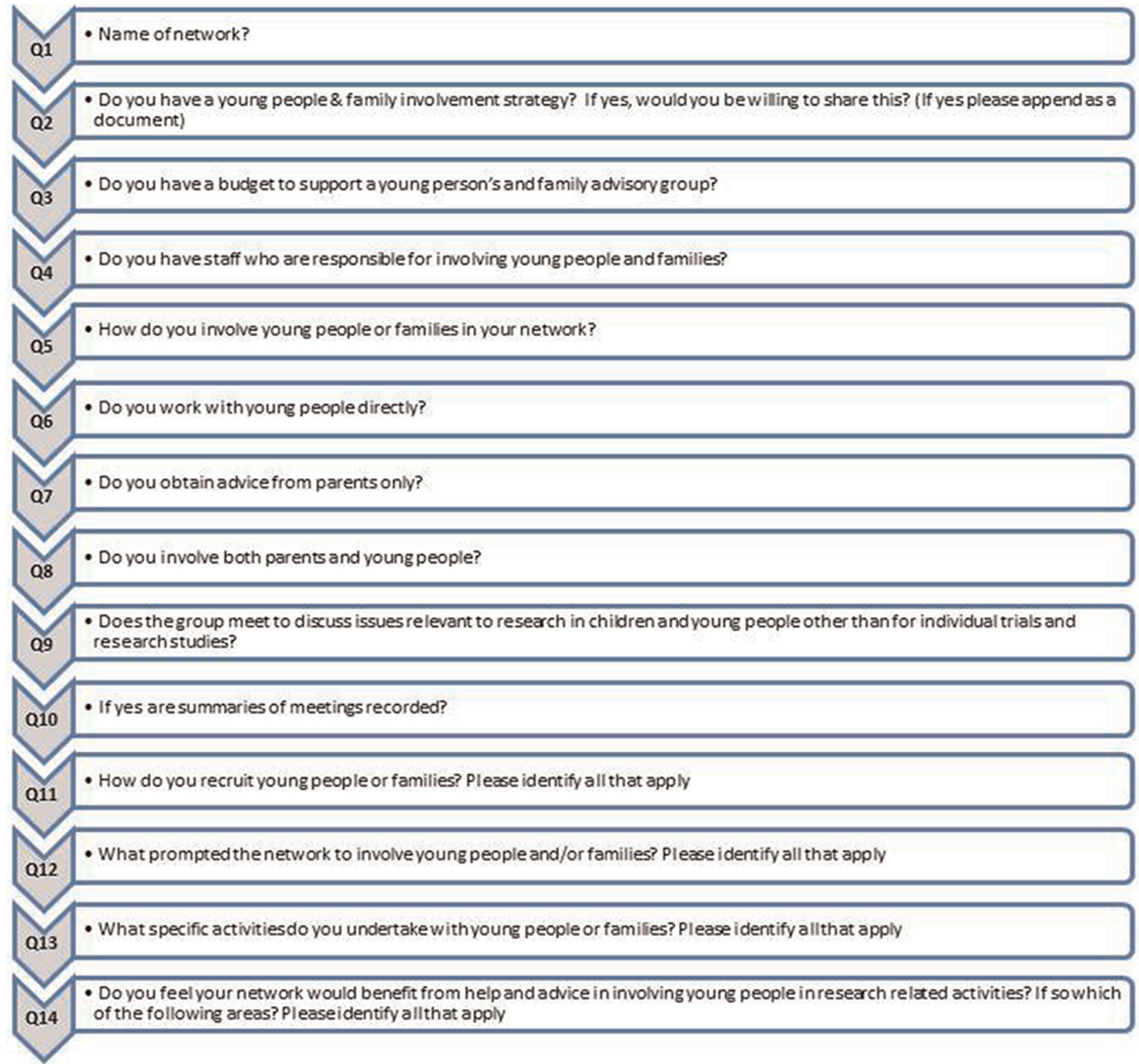

Abstract 0-168a Figure 1 List of survey questions on involvement of young people and family members in the Enpr-EMA paediatric clinical trial networks

Abstract 0-168a Table 2 Specific activities undertaken with young people and family members in Enpr-EMA networks

\begin{tabular}{llll}
\hline Network activities with young people/family members & Total & Yes & No \\
\hline Writing/commenting on participant information leaflets & 17 & 8 & 9 \\
Developing the protocol & 17 & 7 & 10 \\
Disseminating the results & 17 & 6 & 11 \\
Promoting the trial to encourage recruitment & 17 & 8 & 9 \\
Membership of a management/steering/advisory group & 17 & 6 & 11 \\
Priority setting & 17 & 4 & 13 \\
Identifying topics for research & 17 & 3 & 14 \\
Reviewing/interpreting research results & 17 & 2 & 15 \\
\hline
\end{tabular}

\section{REFERENCES}

1 Newman J, Callens C, Tibbins C, and Madge N (2012) Medicines for children: reflecting on how young people improve research. In Fleming J and Boeck T (eds) Involving Children and Young People in Health and Social Care Research, Routledge, London, UK, pp 165-174

2 Enpr-EMA webpages: http://www.ema.europa.eu/ema/index.jsp?curl=pages/partners_and_networks/general/general_content_000303.jsp and mid $=W C 0$ b01 ac05801df74a

3 The Scottish Children's Research Network (ScotCRN) Young Persons Group. Available at: http://www.scotcrn.org/young-people/straegy-documentation/

4 Medicines for Children Research Network Consumer Involvement Strategy 2012 2015. Available at: http://www.mcrn.org.uk/images/stories/consumer/consumer_strategy_sept_2013_jn1.pdf

5 Mother Infant Child Youth Research Network: Young Persons as Research Ambassadors and Advisors. Available at: http://www.micyrn.ca/CreatingAndConnectingNetwork.asp 


\section{Exercise Related Problems in Children}

\section{0-169 EARLY PROGRAMMING OF PHYSICAL ACTIVITY AND SEDENTARY BEHAVIOUR AT PRIMARY SCHOOL AGE. THE ABCD-STUDY}

${ }^{1}$ AW van Deutekom, ${ }^{2} \mathrm{M}$ Chin-A-Paw, ${ }^{3} \mathrm{TGM}$ Vrijkotte, ${ }^{4}$ RJBJ Gemke. ${ }^{1}$ Pediatrics, VU University Medical Center, Amsterdam, Netherlands; ${ }^{2}$ Public Health and EMGO+, VU University Medical Center, Amsterdam, Netherlands; ${ }^{3}$ Public Health, Academic Medical Center, Amsterdam, Netherlands; ${ }^{4}$ Pediatrics and EMGO+, VU University Medical Center, Amsterdam, Netherlands

\subsection{6/archdischild-2014-307384.238}

Background and aims Energy balance may be affected by developmental (re)programming of physical activity and sedentary behaviour, hence predispose for cardiovascular disease in later life. We hypothesise that low birth weight and accelerated growth in infancy corresponds with lower physical activity levels and more sedentary behaviour at $8-9$ years of age, thereby predisposing for obesity.

Methods Physical activity and sedentary behaviour were measured in 183 children (100 boys) of a prospective birth cohort at mean age 8.7 years using accelerometery. Outcomes were minutes per day above moderate activity ( $>3000$ counts $/ \mathrm{min})$ and minutes sedentary per day .

Results On average $( \pm S D)$, children participated in $37( \pm 14)$ minutes of physical activity and $412( \pm 45)$ minutes of sedentary behaviour per day. Low birth weight was not associated with either physical activity or sedentary time. The average standardised growth velocity, however, was positively associated with sedentary time, with an average increase of $7.8 \mathrm{~min}$ in daily sedentary time per SD weight gain in infancy. Growth velocity was not significantly associated with physical activity.

Conclusions Infant growth may program sedentary behaviour, but not physical activity levels at age 8-9. Birth weight was not related to either physical activity or sedentary behaviour. Hence developmental effects of growth on childhood energy balance correspond with variations in sedentary behaviour rather than physical activity.

\section{0-170 GESTATIONAL AGE IS ASSOCIATED WITH PHYSICAL ACTIVITY AND FITNESS IN ADOLESCENCE - NORTHERN FINLAND BIRTH COHORT 1986}

${ }^{1} \mathrm{M}$ Tikanmäki, ${ }^{2} \mathrm{~T}$ Tammelin, ${ }^{3} \mathrm{M}$ Vääräsmäki, ${ }^{1} \mathrm{M}$ Sipola-Leppänen, ${ }^{4} \mathrm{~A}$ Pouta, ${ }^{5} \mathrm{M}$ Järvelin, ${ }^{1}$ E Kajantie. ' Chronic Disease Prevention, National Institute for Health and Welfare, Oulu and Helsinki, Finland; ' ${ }^{2}$ IKES, Research Center for Sport and Health Sciences, Jyväskylä, Finland; ${ }^{3}$ Department of Obstetrics and Gynaecology, Oulu University Hospital, Oulu, Finland; ${ }^{4}$ Children Youth and Families, National Institute for Health and Welfare, Oulu, Finland; ${ }^{5}$ Department of Epidemiology and Biostatistics, Imperial College, London, UK

\subsection{6/archdischild-2014-307384.239}

Background and aims Severely preterm birth is associated with low physical activity and cardiorespiratory fitness. We studied the association of gestational age across its full range with physical activity (self-reported) and cardiorespiratory fitness in adolescence.

Methods Of the 16-year-old members of the population-based Northern Finland Birth Cohort 1986, 6675 singletons with no major physical disability reported the amount of light, brisk and commuting physical activity outside school hours and 4706 completed a submaximal cycle ergometer test for the assessment of cardiorespiratory fitness. Physical activity was summarised as
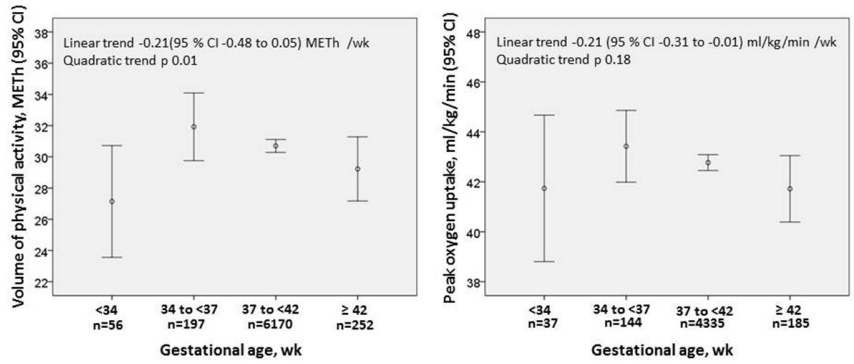

Abstract 0-170 Figure 1 Mean volume of physical activity (METh) per week and peak oxygen uptake $(\mathrm{ml} / \mathrm{kg} / \mathrm{min} /)$ with $95 \%$ confidence intervals in 4 categories of gestational age

metabolic equivalent hours (METhours) per week and peak oxygen uptake relative to body weight $(\mathrm{ml} / \mathrm{kg} / \mathrm{min}$ ) calculated by heart rate responses. To assess the effect of gestational age on the outcomes, the adequate data were analysed by multiple linear regression.

Results There was an inverse U-shaped association between gestational age and physical activity such that adolescents born at both ends of the full range of gestational age undertook less physical activity than others (Figure). These adolescents also seemed to have low cardiorespiratory fitness; however only the linear inverse trend was statistically significant (Figure), suggesting low fitness in those born later gestational ages.

Conclusion Our results are consistent with previous findings of low levels of physical activity in adolescents born severely preterm. We found no evidence of low physical activity and fitness among adolescents born less preterm. Our results also suggest lower physical activity and fitness among adolescents born at later gestational ages; this was post hoc and requires replication.

\section{Gastroenterology II}

\section{0-171 THE COMBINED ROLE OF NORMAL BIRTH AND BREASTFEEDING IN ACUTE EARLY CHILDHOOD GASTROENTERITIS}

${ }^{1} \mathrm{~N}$ Nassar, ${ }^{1} \mathrm{JP}$ Bentley, ${ }^{2} \mathrm{JM}$ Simpson, ${ }^{3} \mathrm{JR}$ Bowen, ${ }^{4} \mathrm{JM}$ Morris, ${ }^{1} \mathrm{CL}$ Roberts. ${ }^{1}$ Clinical and Population Perinatal Health Research, University of Sydney, Sydney, Australia; ${ }^{2}$ School of Public Health, University of Sydney, Sydney, Australia; ${ }^{3}$ Department of Neonatology, Royal North Shore Hospital, Sydney, Australia; ${ }^{4}$ Kolling Institute, University of Sydney, Sydney, Australia

\subsection{6/archdischild-2014-307384.240}

Background Clinical studies have shown prematurity, birth via caesarean section (CS) and exposure to breastmilk impact the establishment of gut microbiota and immune system in early life and increase susceptibility to acute gut infections. This study aims to investigate the combined association of mode, timing of birth and breastfeeding with acute gastroenteritis (AGE) in early childhood.

Method We conducted a population-based cohort study of 893,360 infants born in New South Wales, Australia, 20012011. Data was ascertained via record-linkage of administrative birth, hospital and death data. Follow-up was based on time between discharge at birth to first admission of AGE, sixth birthday, death or study end-date (30/06/2012). Multivariable Cox regression was used to estimate risk of AGE admission adjusted for maternal, obstetric and birth factors.

Results In 2001-2011, there were 41,274 (4.6\%) hospital admissions for AGE in childhood; two-thirds admitted. 